Research Article

\title{
Design Optimization of an Integrated E-Type Multilink Suspension Wheel-Side Drive System and Improvement of Vehicle Ride Comfort
}

\author{
Wen Lu $\left(\mathbb{D},{ }^{1}\right.$ Wenbo Li $\mathbb{D}^{2},{ }^{2}$ and Xinbo Chen $\mathbb{D}^{2}$ \\ ${ }^{1}$ Institute of Automotive Technology, Wuxi Vocational Institute of Commerce, Wuxi 214153, China \\ ${ }^{2}$ School of Automotive Studies, Tongji University, Shanghai 201804, China \\ Correspondence should be addressed to Xinbo Chen; austin_1@163.com
}

Received 10 April 2021; Revised 20 July 2021; Accepted 27 July 2021; Published 18 August 2021

Academic Editor: Mohamed A. A. Abdelkareem

Copyright (C) $2021 \mathrm{Wen} \mathrm{Lu}$ et al. This is an open access article distributed under the Creative Commons Attribution License, which permits unrestricted use, distribution, and reproduction in any medium, provided the original work is properly cited.

Distributed-drive electric vehicles constitute an important research direction for the future development of electric vehicles. In this regard, the integrated suspension wheel-side drive system has considerable development potential because it can address the lack of driving smoothness and the grounding deterioration caused by the excessive unsprung mass of the distributed-drive system. However, a complete and systematic description of the design of such a system is not available in the literature. Therefore, this paper proposes a design process for an integrated E-type multilink suspension wheel-side drive system and a method to improve the vehicle ride comfort. Based on a configuration analysis of the E-type multilink suspension using the orientation feature set method, the ADAMS platform was used to optimize the hard point coordinates of the suspension with the integrated Etype multilink suspension wheel-side drive system as the object, and the spring stiffness and damper were designed considering the driving smoothness and the grounding of the vehicle. The bushing stiffnesses were determined through tests, and the feasibility of each bushing installation was determined via elastic kinematic simulation of the integrated E-type multilink wheel-side drive system; then, optimization design of bushing stiffness was carried out for ride smoothness. Then, a lightweight design of the gears' reducer was performed. Finally, the specific structural design and strength verification of the key components of the designed system were conducted. The results indicated that the strength of each component of the wheel-side drive system met the requirements. Thus, the overall design process of the integrated suspension wheel-side drive system was improved. This study can therefore serve as a reference for the integrated design and vehicle ride comfort improvement of wheel-side drive systems and suspensions.

\section{Introduction}

Distributed-drive electric vehicles have a short drive chain, compact structure, and high-efficiency transmission, which are important for the development of future electric vehicles [1]. In the same time, four-wheel independently actuated electric vehicles employ four in-wheel motors for direct propulsion, and the output torque of each wheel motor can be controlled independently and precisely $[2,3]$. Some control methods were proposed to improve the yaw stability, such as PI-based control strategy [4], second-order sliding mode [5], adaptive model predictive control (AMPC) scheme [6], and hybrid control-based acceleration slip regulation (ASR) method [7]. However, existing distributed electric drive systems commonly suffer from the negative effects of vertical dynamics due to large unsprung masses, resulting in increased dynamic loads on the drive wheels, deterioration of grounding performance, and reduced driving smoothness $[8,9]$.

To mitigate the negative effects of unsprung mass, research is being conducted in four main directions in China and other countries: integrated design of the wheel-side drive system and suspension [10-12], application of new lightweight materials [13], development of high-powerdensity motor technology [14], and control of active and semiactive suspensions $[15,16]$. Among these, the 
integration of suspension and wheel-side drive system is an effective method to reduce the large unsprung mass of existing distributed-drive electric vehicles. Herein, an integrated suspension wheel-side drive system scheme is proposed.

The multilink suspension is a high-performance suspension that affords considerable flexibility and can be tuned for different types of vehicles [17]. Schemes for integrating different multilink suspensions with wheel-side drive systems have been studied by Prof. Chen Xinbo's team [18-23]. Besides, Chen et al. studied the integrated multilink suspensions on suppression of the negative effect of the unsprung mass by theoretical analysis with lump parameter models $[24,25]$. While, in the previous studies, the integrated E-type multilink independent suspension and its influence on the negative effect of the unsprung mass has not been studied.

A suspension has a complex spatially parallel mechanism topology. The mechanism topology theory can express the spatial mechanism topology mathematically, which considerably simplifies the system topology, kinematics, and dynamics formulation and provides a scientific method for system topology innovation as well as theoretical support for designing innovative suspension structures [26].

In this study, the integrated E-type multilink independent suspension was designed, and its suppression on the negative effect of the unsprung mass was analyzed by multibody dynamics analysis. First, the mechanism topology theory was applied to this system to analyze its spatial topology. Then, a kinematic simulation model of the integrated system was established in ADAMS/View, while comprehensively considering the wheel-positioning parameters, and the system was optimized to obtain the hard point parameters of the suspension. The spring stiffness and damping parameters were optimized with comprehensive consideration of the driving smoothness and wheel grounding. Thereafter, a comparison between the proposed system and a wheel motor drive system of equal mass revealed that the negative effect of the unsprung mass was significantly suppressed. A stiffness measurement test was conducted on the bushing to determine the required bushing stiffness, and the feasibility of each bushing adopted in the proposed suspension model was verified through elastic kinematics analysis of the suspension. Then, optimization design of bushing stiffness was carried out to improve the ride comfort. To further mitigate the negative effect of excessive unsprung mass, the gears were lightweighted via nonlinear programming. Finally, the structural design and strength verification of the components of the integrated Etype multilink suspension wheel-side drive system were performed.

\section{Design and Topological Mechanism Analysis of an Integrated E-Type Multilink Suspension Wheel-Side Drive System}

Distributed-drive electric vehicles commonly suffer from a large unsprung mass and high system cost, which directly limit the consumer demand for such vehicles. Integration of the wheel-side drive system with the suspension can effectively mitigate the negative impact of unsprung mass. In this study, an integrated E-type multilink suspension wheelside drive system (Figure 1) was designed.

In this system, the function of the trailing arm is realized by the reducer housing (the housing of the (iii) reducer), which is connected to the frame by a linear pair through an adapter plate. The motor housing is solidly connected to the reducer housing. The upper, front-lower, and rear-lower control arms are each connected by a spherical hinge to the frame at one end and to the reducer at the other end. The reducer output shaft is connected to the wheel bearing. The fixed part of the wheel bearing is connected to the integrated trailing arm, and the reducer output shaft drives the rotating part of the wheel bearing and the wheel rim through splines. The power is output from the motor, the motor output shaft acts directly as the reducer input shaft (or the motor output shaft is connected to the reducer input shaft by a coupling), and the motor power is transmitted to the wheel rim through the reducer output shaft after speed reduction and torque multiplication by the reducer. In the actual solution, all kinematic pairs are in the form of rubber bushings.

The topological characteristics of the mechanism are inherent topological invariants of the parallel mechanism, which reflect the basic characteristics of the structure, kinematics, and dynamics of the parallel mechanism. A mechanism topological analysis can be performed when the suspension jump has one degree of freedom, which meets the requirements for automotive suspension design, as determined by Wang [27].

As the motor and reducer are solidly integrated in the trailing arm, the motor-reducer-trailing arm can be considered as a single component, hereinafter referred to as the "integrated trailing arm." The system topology is shown in Figure 2.

In Figure 2, $S_{i j}$ is the spherical pair, $R_{i j}$ is the rotation pair, $P_{i j}$ is the prismatic pair, $i$ is the part number, and $j$ is the pair number. The upper control arm (i), front-lower control arm (ii), and rear-lower control arm (iii) are each connected by a spherical hinge to the frame, as well as to the integrated trailing arm (iv). The integrated trailing arm (iv) is connected to the frame with a linear pair, that is, rotation is possible in three directions and movement along a certain linear direction. Rubber bushings may be considered for the various kinematic pairs in the suspension when specifically implemented.

The proposed integrated E-type multilink suspension wheel-side drive system was topologically analyzed. The system has four branches. The upper, front-lower, rearlower, and integrated trailing arms are located in the first, second, third, and fourth branches, respectively, and the topology of each branch is $\operatorname{SOC}\left\{-S_{i 1}-S_{i 2}-\right\},(i=1 \sim 3)$ SOC $\{-\overbrace{R_{41} R_{42} R_{43}}-P_{44}-\}$, where SOC is single open-chain structural unit. The base point on the moving platform is chosen to be any fixed point on the wheel. The orientation feature set of the end-members of the first, second, and third branches is 


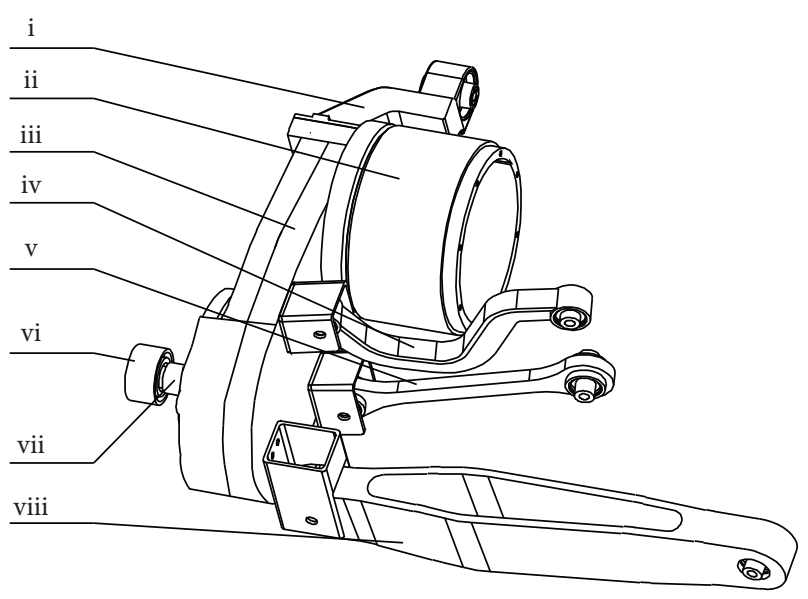

FIGURE 1: Integrated E-type multilink suspension wheel-side drive system with (i) bushing adapter plate, (ii) motor, (iii) reducer, (iv) upper control arm, (v) front-lower control arm, (vi) wheel bearing, (vii) reducer output shaft, and (viii) rear-lower control arm.

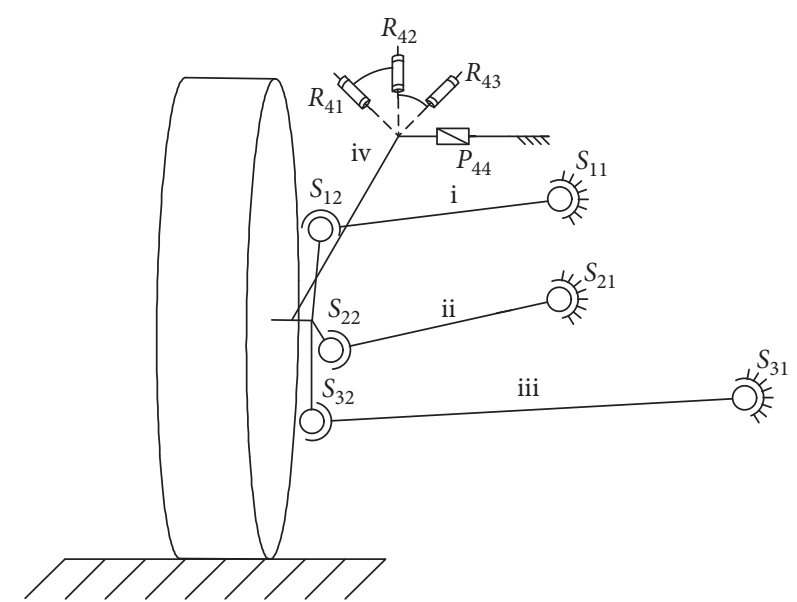

FIGURE 2: Sketch of the topology of the integrated E-type multilink suspension wheel-side drive system with (i) the upper control arm, (ii) front-lower control arm, (iii) rear-lower control arm, and (iv) integrated trailing arm.

$$
M_{b i}=\left[\begin{array}{l}
t^{2} \\
r^{3}
\end{array}\right] \cup\left[\begin{array}{l}
t^{2} \\
r^{3}
\end{array}\right]=\left[\begin{array}{l}
t^{3} \\
r^{3}
\end{array}\right], \quad(i=1 \sim 3),
$$

where $M$ is the orientation feature set, $t$ is the orientation feature of the prismatic pair, $r$ is the orientation feature of the rotation pair. The superscripts 2 and 3 are the number of the orientation features of the pair.

The orientation feature set of the end member of the fourth branch $M_{b 4}$ is

$$
\begin{aligned}
M_{b 4}= & {\left[\begin{array}{c}
t^{1}\left(\perp\left(R_{41}, \rho_{41}\right)\right) \\
r^{1}\left(\| R_{41}\right)
\end{array}\right] \cup\left[\begin{array}{c}
t^{1}\left(\perp\left(R_{42}, \rho_{42}\right)\right) \\
r^{1}\left(\| R_{42}\right)
\end{array}\right] } \\
& \cup\left[\begin{array}{c}
t^{1}\left(\perp\left(R_{43}, \rho_{43}\right)\right) \\
r^{1}\left(\| R_{43}\right)
\end{array}\right] \cup\left[\begin{array}{c}
t^{1}\left(\| P_{44}\right) \\
r^{0}
\end{array}\right]=\left[\begin{array}{c}
t^{3} \\
r^{3}
\end{array}\right],
\end{aligned}
$$

where $\left\{t^{1}(\perp(R, \rho))\right\}$ indicates that the base point of the component moves in the direction perpendicular to the axis $R$ and the radial vector $\rho$, and it is a nonindependent element. $r^{1}(\| R)$ indicates that there is a rotation in the direction parallel to the $R$-axis, and it is an independent element.

According to the mechanism-composition principle of the parallel mechanism, the first and second branches, as well as the moving and fixed platforms, form the first independent circuit. For this circuit, the number of independent displacement equations $\xi_{L 1}$ is

$$
\xi_{L 1}=\operatorname{dim}_{\bullet}\left\{M_{b 1} \cup M_{b 2}\right\}=\operatorname{dim}_{\bullet}\left\{\left[\begin{array}{l}
t^{3} \\
r^{3}
\end{array}\right]\right\}=6,
$$

where $\operatorname{dim}_{\bullet}\{\}$ is the dimension of orientation characteristics. $M_{b 1} \cup M_{b 2}$ is the orientation feature set of the end members of the series mechanism.

Thus, the number of degrees of freedom of the subparallel mechanism consisting of the first and second branches is

$$
F_{(1-2)}=\sum_{i=1}^{4} f_{i}-\sum_{j=1}^{1} \xi_{L j}=12-6=6,
$$

where $F_{(1-2)}$ is the number of degrees of freedom of the subparallel mechanism consisting of the first and second branches. $f_{i}$ is the freedom of the $i$ th kinematic pair.

Similarly, the third branch connects the moving and fixed platforms to constitute the second independent circuit, which has six independent displacement equations and a parallel mechanism with six-degrees of freedom. The fourth branch connects the moving and fixed platforms to constitute the third independent circuit, which has six independent displacement equations and a parallel mechanism with four degrees of freedom.

Disregarding the local degrees of freedom in the first, second, and third branches, the E-type multilink independent suspension guidance mechanism has one enddegree of freedom. The set of orientation characteristics of the end member is

$$
M_{P a}=M_{P a(1-2)} \cap M_{b 3}=\left[\begin{array}{l}
t^{3} \\
r^{3}
\end{array}\right] \cap\left[\begin{array}{l}
t^{3} \\
r^{3}
\end{array}\right]=\left[\begin{array}{l}
t^{3} \\
r^{3}
\end{array}\right],
$$

where $M_{P a}$ is the set of orientation characteristics of the end member. $M_{P a(1-2)}$ is the set of orientation characteristics of the subparallel mechanism consisting of the first and second branches. $M_{b 3}$ is the set of orientation characteristics of the end member of the third branch.

Therefore, the integrated E-type multilink suspension wheel-side drive system has one jerk degree of freedom, three directions of linear movement, and three directions of rotation, which meet the design requirements for automotive suspensions. 


\section{Kinematic Analysis and Optimization of the Integrated E-Type Multilink Suspension Wheel-Side Drive System}

The kinematic characteristics of the suspension considerably influence the maneuverability and driving smoothness of the entire vehicle. Thus, a kinematic analysis and optimization of the integrated E-type multilink suspension wheel-side drive system are required.

First, the integrated E-type multilink suspension wheelside drive system was reasonably simplified to a $1 / 4$-scale vehicle model, assuming the same road unevenness function at each wheel joint and independent forces on each suspension. In the kinematic analysis, the effect of the bushings on the amount of wheel jerk in relation to the hard point coordinates was minimal; thus, the effect of the rubber bushings was neglected.

The kinematic model of the integrated E-type multilink suspension wheel-side drive system was built in ADAMS/View, and the coordinates of each positioning point were determined. Among them, the body hard points included the hinge point TA_Body between the integrated trailing arm and the body, the hinge point UCA_Inner between the upper control arm and the body, the hinge point QLCA_Inner between the front-lower control arm and the body, and the hinge point HLCA_Inner between the rear-lower control arm and the body. The wheel end positioning points include the wheel center Wheel_Center, the hinge point UCA_Outer between the upper control arm and the integrated trailing arm, the hinge point QLCA_Outer between the frontlower control arm and the integrated trailing arm, and the hinge point HLCA_Outer between the rear lower control arm and the integrated trailing arm. Referring to the technical data of a model, the coordinates of each positioning point were determined with the wheel center point as the origin and are shown in Table 1.

The ADAMS/View kinematic model of the integrated Etype multilink suspension wheel-side drive system is shown in Figure 3.

When a vehicle is running, the wheel camber angle, toe-in angle, and wheelbase variation have a significant influence on the driving performance, particularly the handling stability. Therefore, these parameters were selected as the optimization objectives, and the target was to minimize their variation. A wheel jerk simulation was performed in ADAMS/View, and the range of wheel jerk was determined according to the possible range of actual wheel jerk, which was $\pm 50 \mathrm{~mm}$. An analysis of the sensitivity of the body hard point coordinates to the optimization objectives was performed using ADAMS/ Insight; the variables UCA_Innerx, UCA_Innery, UCA_Innerz, QLCA_Innerx, QLCA_Innery, QLCA_Innerz, HLCA_Innerx, and HLCA_Innery, which had a sensitivity higher than $15 \%$, were selected as the optimization variables, and the respective optimization ranges were determined. Using ADAMS/Insight, the interaction model fitting of each optimization objective with respect to each optimization variable was performed, and the fitting function of each optimization objective was obtained. As there were contradictions among the wheel camber angle $y 1$, toe-in angle $y 2$, and wheelbase variation $y 3$ and because the optimal solutions could not be obtained simultaneously, the unified objective method was adopted to establish the total unified objective function. First, the importance of each subobjective was considered to determine the value range of each subobjective; then, the index tolerance value and weighting factor for each subobjective were calculated. The results are shown in Table 2.

The final optimization objective function was determined to be

$$
Y=y_{1}+4 y_{2}+0.04 y_{3} \text {, }
$$

where $y_{i}$ is the optimization objective and $i=1,2,3$.

Genetic algorithm was used for optimization. And, the optimized suspension positioning point parameters were obtained, as shown in Table 3.

Comparing the wheel-positioning parameters before and after optimization, the following observations can be made from Figure 4 and Table 4:

(1) Wheel camber angle: to improve the directional stability of the wheel under longitudinal force during braking and to reduce tire wear, the camber angle variation should be restricted to $2^{\circ}$ with a reasonable variation tendency. From Figure 4(a) and Table 4, it can be seen that the range of the wheel camber angle variation with the bump and rebound changed from $3.35^{\circ}$ before optimization to only $0.17^{\circ}$ after the optimization of the integrated E-type multilink suspension wheel-side drive system, with a reasonable variation tendency.

(2) Wheel toe-in angle: the toe-in angle of the rear wheels, which promotes understeer, is primarily designed to have a weak positive variation at the bump and should be no more than $0.3^{\circ}$ at the bump. From Figure 4(b) and Table 4, it can be seen that the toe-in angle of the proposed integrated system was restricted to $0.07^{\circ}$ with a weak positive toe-in variation during bump; moreover, the range of wheel toe-in angle variation with the bump and rebound of the wheel changed from $1.17^{\circ}$ before optimization to only $0.55^{\circ}$ after optimization, which meets the relevant design requirement.

(3) Wheelbase variation: to reduce tire wear and improve driving stability, the wheelbase variation should be minimal; the single wheelbase variation for a general vehicle should be within $10 \mathrm{~mm}$. From Figure 4(c) and Table 4, it can be seen that the wheelbase variation of the integrated E-type multilink suspension wheel-side drive system was restricted to $8.5 \mathrm{~mm}$, which meets the design requirements. Thus, the hard point parameters of this system were determined. 
TABLE 1: Parameters of the modeled positioning points.

\begin{tabular}{lccc}
\hline Point & $X(\mathrm{~mm})$ & $Y(\mathrm{~mm})$ & $Z(\mathrm{~mm})$ \\
\hline UCA_Outer & 58.00 & 90.00 & -67.00 \\
UCA_Inner & 361.00 & 90.00 & -90.00 \\
QLCA_Outer & 49.00 & -111.00 & -88.00 \\
QLCA_Inner & 340.00 & -59.00 & -101.00 \\
HLCA_Outer & 49.00 & -113.00 & 61.00 \\
HLCA_Inner & 612.00 & -28.00 & 54.00 \\
TA_Body & 115.00 & -23.00 & -433.00 \\
Wheel_Ground & 0.00 & -362.15 & 0.00 \\
\hline
\end{tabular}

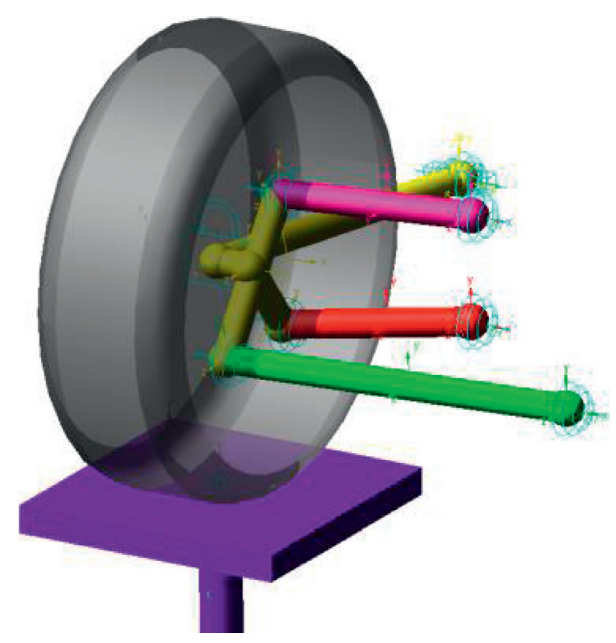

FIGURE 3: Kinematic model of the integrated E-type multilink suspension wheel-side drive system.

TABLE 2: Weighting factors for each optimization objective.

\begin{tabular}{lccc}
\hline Optimization goal & Value range & Tolerance limit & Weighting factor \\
\hline Wheel camber angle & {$[-1,1]$} & 1 & 1 \\
Wheel toe-in angle & {$[-0.5,0.5]$} & 0.5 & 4 \\
Wheelbase variation & {$[-5,5]$} & 5 & 0.04 \\
\hline
\end{tabular}

TABLE 3: Optimized suspension positioning point parameters.

\begin{tabular}{lccc}
\hline Point & $X(\mathrm{~mm})$ & $Y(\mathrm{~mm})$ & $Z(\mathrm{~mm})$ \\
\hline Wheel_Center & 0.00 & 0.00 & 0.00 \\
UCA_Outer & 58.00 & 90.00 & -67.00 \\
UCA_Inner & 351.33 & 89.00 & -140.00 \\
QLCA_Outer & 49.00 & -111.00 & -88.00 \\
QLCA_Inner & 340.90 & -71.00 & -150.98 \\
HLCA_Outer & 49.00 & -113.00 & 61.00 \\
HLCA_Inner & 613.00 & -72.70 & 54.00 \\
TA_Body & 115.00 & -23.00 & -433.00 \\
Wheel_Ground & 0.00 & -362.15 & 0.00 \\
\hline
\end{tabular}

\section{Elastic Element Design and Elastic Dynamics Analysis of the Integrated E-Type Multilink Suspension Wheel-Side Drive System}

To improve the ride smoothness and wheel grounding of the integrated E-type multilink suspension wheel-side drive system, a suitable design for the elastic elements of the system is required. Thus, a design analysis of the elastic elements was performed for only two parts, the system spring damper and the bushing.

4.1. Position Arrangement and Parameter Matching Design of Spring Damper. To simplify the box structure and create space for mounting electric vehicle-specific components 


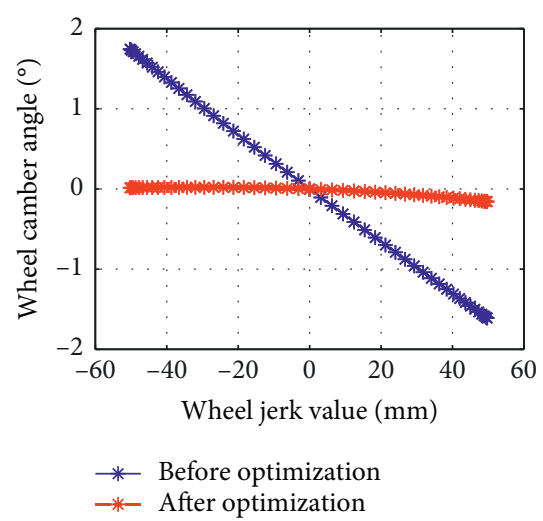

(a)

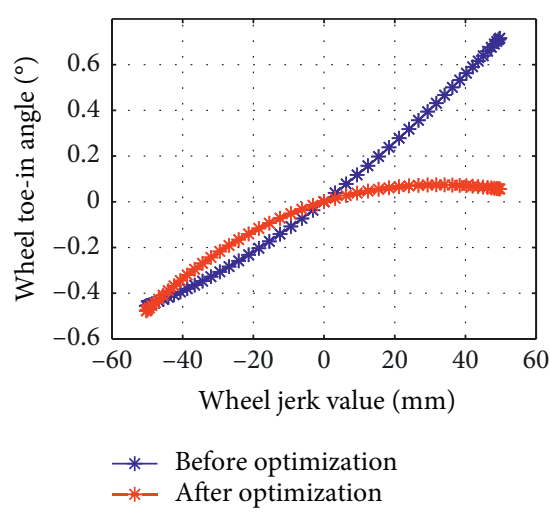

(b)

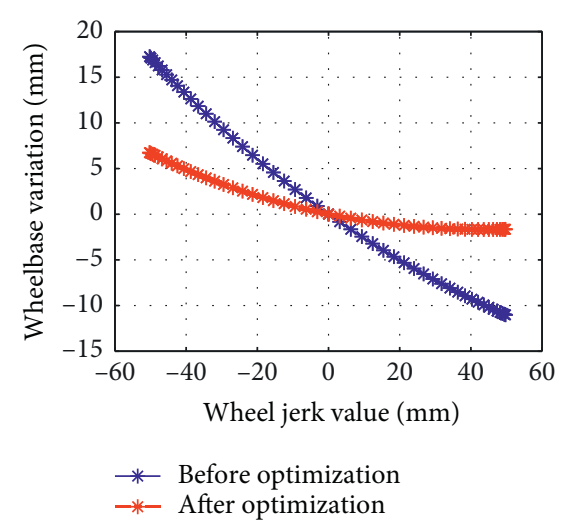

(c)

Figure 4: Comparison of (a) wheel camber angle, (b) wheel toe-in angle, and (c) wheelbase variation before and after optimization.

TABLE 4: Comparison of wheel alignment parameters before and after optimization.

\begin{tabular}{clccc}
\hline Wheel alignment parameters & Wheel camber angle $\left(^{\circ}\right)$ & Wheel toe-in angle $\left(^{\circ}\right)$ & Wheelbase variation $(\mathrm{mm})$ \\
\hline \multirow{2}{*}{ Bump } & Preoptimization & -1.6091 & 0.7153 & -11.0523 \\
& Postoptimization & -0.1556 & 0.0732 & -1.7045 \\
& Preoptimization & 1.7457 & -0.4558 & 17.2538 \\
Rebound & Postoptimization & 0.0218 & -0.4781 & 6.7380 \\
\hline \multirow{2}{*}{ Largest quantity of } & Preoptimization & 3.3547 & 1.1711 & 28.3062 \\
change & Postoptimization & 0.1774 & 0.5513 & 8.4425 \\
\hline Optimization degree & Optimization value & 3.1773 & 0.6198 & 19.8637 \\
(level or extent) & Optimization rate & $94.71 \%$ & $52.92 \%$ & $70.17 \%$ \\
\hline
\end{tabular}

such as motor controllers, the spring damper was designed as an assembly, mounted in collineation, with its abutment mounted on the rear-lower control arm. The spring damper arrangement parameters were set based on the chassis arrangement of the model, as shown in Table 5 .

The stiffness and damping of the integrated E-type multilink suspension wheel-side drive system have critical impact on the vertical dynamics during driving, including the ride smoothness and wheel grounding. Based on the kinematic analysis model, the body members were added, springs included added between the wheels and the test platform to simulate the tire stiffness $(200 \mathrm{~N} / \mathrm{m})$, and spring and damper were added between the rear-lower control arm and the body members (the values need to be determined through optimization design) to obtain the wheel-body multibody dynamics model of the proposed suspension, as shown in Figure 5. In addition, the value of each inertia parameter was obtained based on the actual measurements of the single longitudinal arm integrated prototype already available, as shown in Table 6. The masses and rotational inertias of the upper, front-lower, and rear-lower control arms were neglected.

In addition, filtered white noise pavement and a vehicle speed of $60 \mathrm{~km} / \mathrm{h}$ were considered in the pavement model, which was simulated on a Class-B pavement.

The values of bias frequency are generally between 0.9 and $1.6 \mathrm{~Hz}$ for modern sedans [28]. The design equation for the stiffness of the integrated E-type multilink suspension wheel-side drive system is
TABle 5: Upper and lower pivot point positions of the spring damper.

\begin{tabular}{lccc}
\hline Design point parameters & $X(\mathrm{~mm})$ & $Y(\mathrm{~mm})$ & $Z(\mathrm{~mm})$ \\
\hline Spring damper upper pivot point & 246.95 & 279.43 & 80.49 \\
Spring damper lower pivot point & 250.95 & -98.57 & 58.49 \\
\hline
\end{tabular}

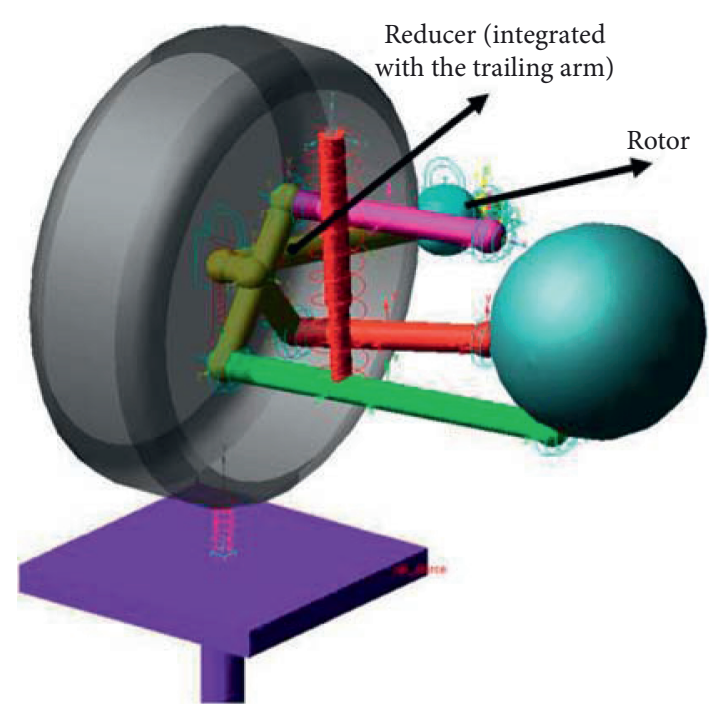

FIGURE 5: Dynamics model of the integrated E-type multilink suspension wheel-side drive system. 
TABLE 6: Component parameters of the integrated E-type multilink suspension wheel-side drive system.

\begin{tabular}{lc}
\hline Parameters of each component & Value \\
\hline Wheel and rim mass $(\mathrm{kg})$ & 15 \\
$1 / 4$ unladen body mass $(\mathrm{kg})$ & 400 \\
Mass reduction gearbox integrated with trailing arm $(\mathrm{kg})$ & 17 \\
Motor mass $(\mathrm{kg})$ & 29 \\
Tire stiffness $(\mathrm{N} / \mathrm{m})$ & 200 \\
\hline
\end{tabular}

$$
n=\frac{1}{2 \pi} \sqrt{\frac{k}{m}}
$$

where $n, k$, and $m$ are the intrinsic frequency, stiffness, and mass of the rear axle, respectively. As the wheels are symmetrical, $k$ and $m$ can also be interpreted as the stiffness and the spring-loaded mass of the integrated E-type multilink suspension wheel-side drive system. The stiffness $k$ is 12,791 to $40,426 \mathrm{~N} / \mathrm{m}$. For the frictionless elastic element (coil spring), the damping ratio is generally 0.25 to 0.35 , according to the design equation for suspension damping:

$$
c=2 \cdot \psi \cdot m \cdot \omega,(\omega=2 \pi n),
$$

where $c, \psi$, and $\omega$ are the damping, damping ratio, and angular frequency, respectively. The damping value of the suspension damper $c$ is 1191 to $2815 \mathrm{~N} \cdot \mathrm{s} / \mathrm{m}$.

In addition, considering the arrangement of the spring and damper and neglecting their inclination angles, the actual spring stiffness $k_{a}$ and damping values $c_{a}$ can be determined using the following equation:

$$
\begin{aligned}
& k_{a}=k \cdot\left[\frac{l}{a_{1}}\right]^{2}, \\
& c_{a}=c \cdot\left[\frac{l}{a_{2}}\right]^{2},
\end{aligned}
$$

where $l$ is the length of the trailing arm, $a_{1}$ is the distance from the spring to the hinge point of the body, and $a_{2}$ is the distance from the damper to the hinge point of the body. As a result, the value range of $k_{a}$ is 31,040 to $98,103 \mathrm{~N} / \mathrm{m}$, and the value range of $c_{a}$ is 2475 to $6831 \mathrm{~N} \cdot \mathrm{s} / \mathrm{m}$.

Different matches between stiffness and damping lead to changes in the vertical performance of the system. For evaluation of driving smoothness, the total weighted value evaluation method specified in ISO2631 was used, and the weighted body acceleration root mean square (RMS) value $a_{w}$ was used as the evaluation index; for the evaluation of wheel grounding, the total weighted value evaluation method was used, and the dynamic wheel load RMS value $\mathrm{F}_{d}$ was used as the evaluation index. The power spectral density (PSD) of body acceleration and wheel dynamic load under different stiffnesses and dampings were measured using ADAMS/Vibration; the changes in smoothness and grounding indexes of the vehicle were calculated and are shown in Figure 6. In Figure 6, the stiffnesses are shown in different colors with different markers, and for each stiffness, different dampings were set to calculate grounding index and smoothness index, and the dampings are shown in different colors and line types. In other words, for each stiffness and damping, one grounding index and one smoothness index were calculated. For example, when $\left(k_{a}, c_{a}\right)=(64,572 \mathrm{~N} / \mathrm{m}, 4493 \mathrm{~N} \cdot \mathrm{s} / \mathrm{m}), \quad$ the $\quad\left(a_{w}, F_{d}\right)=$ $\left(0.1803 \mathrm{~m} / \mathrm{s}^{2}, 0.2284 \mathrm{kN}\right)$. Then a point on the yellow solid line with diamond mark $\left(k_{a}=64,572 \mathrm{~N} / \mathrm{m}\right)$ was obtained.

As can be seen from Figure 6, the vertical dynamics performance of the suspension considerably varied for different stiffness and damping values. First, the value of spring stiffness has a considerable influence on the vertical dynamics performance. As the stiffness decreases, the smoothness and grounding indexes of the integrated E-type multilink suspension wheel-side drive system simultaneously decreases. Although adjusting the stiffness is one of the basic methods to improve the vertical dynamics performance of a suspension system, a reduction in the stiffness of an integrated system directly leads to an increase in its dynamic deflection. Due to the structural layout constraints, the system has a maximum limit of permissible dynamic deflection. Therefore, the stiffness of this system needs to be optimized to prevent the deflection from exceeding the limit. The limit for modern sedans is 7 to $9 \mathrm{~cm}$ [28]. The dynamic deflection would be calculated after the optimization design of elastic elements including spring and bushings. In contrast, when the stiffness is constant, as the damping value increases, the smoothness index of the vehicle increases, and the grounding index of the wheels decreases. However, as the damping continues to increase, a critical point (the lowest point of the curve in the figure) is reached. Increasing the damping beyond this point leads to a simultaneous deterioration in smoothness and grounding.

Considering the foregoing analysis, a value of $64,572 \mathrm{~N} / \mathrm{m}$ was adopted for the spring stiffness, and a value range of 3964 to $5550 \mathrm{~N} \cdot \mathrm{s} / \mathrm{m}$ was adopted for the damping.

The selection of the damping for the integrated E-type multilink suspension wheel-side drive system requires a combination of the vehicle smoothness index $a_{w}$ and the grounding index $F_{d}$. Thus, an objective function was established as follows:

$$
y=w_{1} \times a_{w}+w_{2} \times F_{d},
$$

where $w_{1}$ is the weight of $a_{w}$, $w_{2}$ is the weight of $F_{d}$, and the $\alpha$ method is used to determine the weights of $a_{w}$ and $F_{d}$. The fundamental concept of the $\alpha$ method is that the weights are assigned such that the ratios of the maximum to minimum values of the different evaluation indicators multiplied by the weights are equal in the simulation process. The optimization result was $K=64,572 \mathrm{~N} / \mathrm{m}, C=4846 \mathrm{~N} \cdot \mathrm{s} / \mathrm{m}$. The corresponding smoothness index was $a_{w}=0.1829 \mathrm{~m} / \mathrm{s}^{2}$, and the corresponding grounding index was $F_{d}=0.2282 \mathrm{kN}$.

Based on the spring stiffness and damping coefficients obtained from the design, further structural design of the spring and damper was performed as per the design process outlined in automotive chassis design [28].

To analyze the suppression of the negative effect of the unsprung mass when using the integrated E-type multilink suspension wheel-side drive system, the vertical dynamics performance of different forms of drive system arrangement schemes were determined. In addition, an equal-mass wheel motor drive system with the same suspension parameters as 


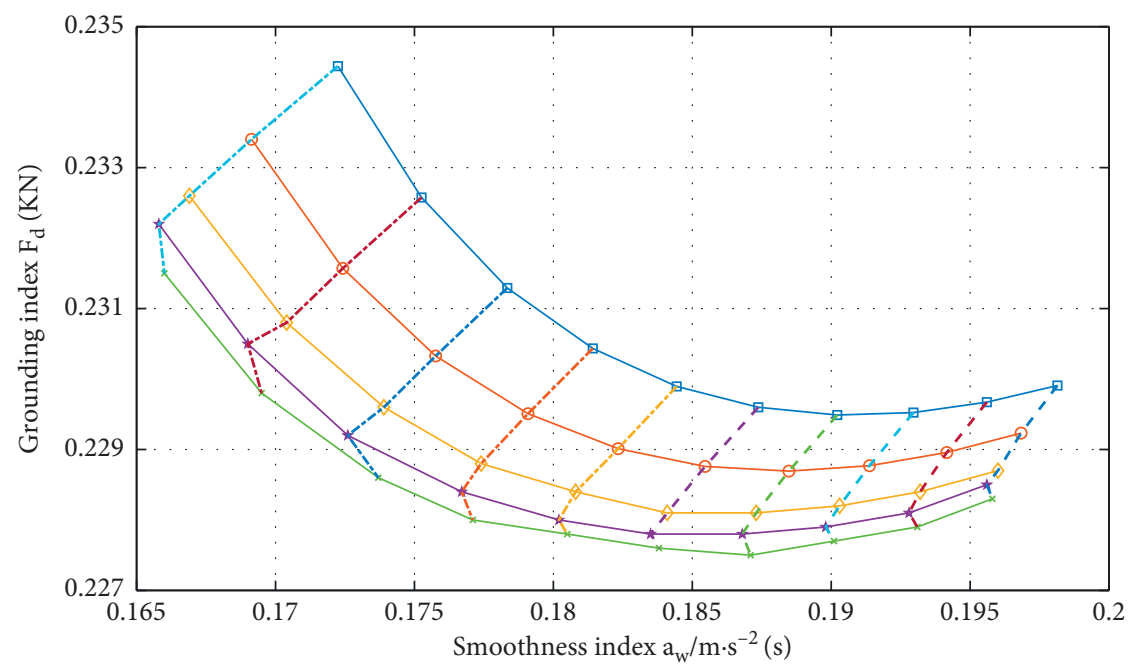

$$
\begin{array}{ll}
\rightarrow & k_{a}=31040 \mathrm{~N} / \mathrm{m} \\
\multimap & k_{a}=47806 \mathrm{~N} / \mathrm{m} \\
\smile-k_{a}=64572 \mathrm{~N} / \mathrm{m} \\
\multimap & k_{a}=81337 \mathrm{~N} / \mathrm{m} \\
\multimap & k_{a}=98103 \mathrm{~N} / \mathrm{m}
\end{array}
$$

$$
\begin{array}{ll}
\ldots & C_{a}=3964 \mathrm{Ns} / \mathrm{m} \\
--- & C_{a}=4141 \mathrm{Ns} / \mathrm{m} \\
--- & C_{a}=4317 \mathrm{Ns} / \mathrm{m} \\
\ldots-- & C_{a}=4493 \mathrm{Ns} / \mathrm{m} \\
--- & C_{a}=4669 \mathrm{Ns} / \mathrm{m}
\end{array}
$$

$$
\begin{aligned}
--C_{a} & =4846 \mathrm{Ns} / \mathrm{m} \\
--C_{a} & =5022 \mathrm{Ns} / \mathrm{m} \\
--C_{a} & =5198 \mathrm{Ns} / \mathrm{m} \\
--\cdot C_{a} & =5374 \mathrm{Ns} / \mathrm{m} \\
--\cdot C_{a} & =5550 \mathrm{Ns} / \mathrm{m}
\end{aligned}
$$

FIGURE 6: Effect of matching different stiffnesses and dampings on the vertical performance index.

those of the proposed system was considered for comparison, which is shown in Figure 7. As shown in Figure 7, the motor and the reducer are inside the wheel for the wheel motor drive system, so their masses are unsprung mass. While for the integrated E-type multilink suspension wheel-side drive system (Figure 5), the reducer housing is regarded as one of the trailing arm and the motor is mounted at its end. So, the masses of the reducer and the motor are transferred on the spring. The detailed explanation can be found in the literature published earlier by our research group [25]. The results of vertical dynamics performance of different drive system arrangement schemes are shown in Figure 8.

As can be seen from Figure 8, compared with the corresponding parameters of the hub motor drive system, the peak power spectral density of the body acceleration near the inherent frequency of wheel vibration was significantly lower, and the resonance frequency increased for the integrated E-type multilink suspension wheel-side drive system; in addition, the peak power spectral density of wheel dynamic load near the inherent frequency of wheel vibration was significantly lower, and the resonance frequency was higher for the proposed system. Therefore, the suppression of the negative effect of unsprung mass by the integrated Etype multilink rear independent suspension wheel-side drive system is significant.

\subsection{Selection and Verification of the Stiffness of the Bushing.} The bushing stiffness was determined via a stiffness test. The specific steps of the test are described elsewhere [29]. The measured six-degree-freedom of bushing stiffnesses of each bushing for the suspension system employed on the Volkswagen PQ35 platform, which is used in this study, are shown in Table 7.

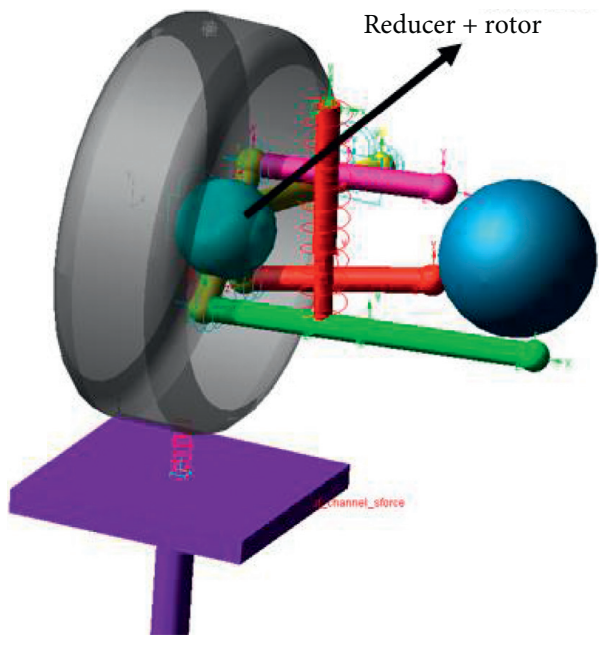

Figure 7: Dynamics model of the wheel motor drive system with the same suspension parameters.

The measured bushing stiffness was considered for the integrated E-type multilink suspension wheel-side drive system. Bushing 1 was used for the kinematic pair at the hinge point of the front-lower control arm and the body; bushing 2 was used for the kinematic pairs at the hinge point of the front-lower control arm and integrated trailing arm (2-1\#) and the hinge point of the rear-lower control arm and integrated trailing arm (2-2\#); bushing 3 was used for the kinematic pair at the hinge point of the upper control arm and integrated trailing arm; bushing 4 was used for the kinematic pair at the hinge point of the upper control arm and the body; bushing 5 was used for the kinematic pair at the hinge point of the integrated trailing arm and the body; and bushing 6 was used for the kinematic pair at the hinge point of the rear-lower control arm and the body. 


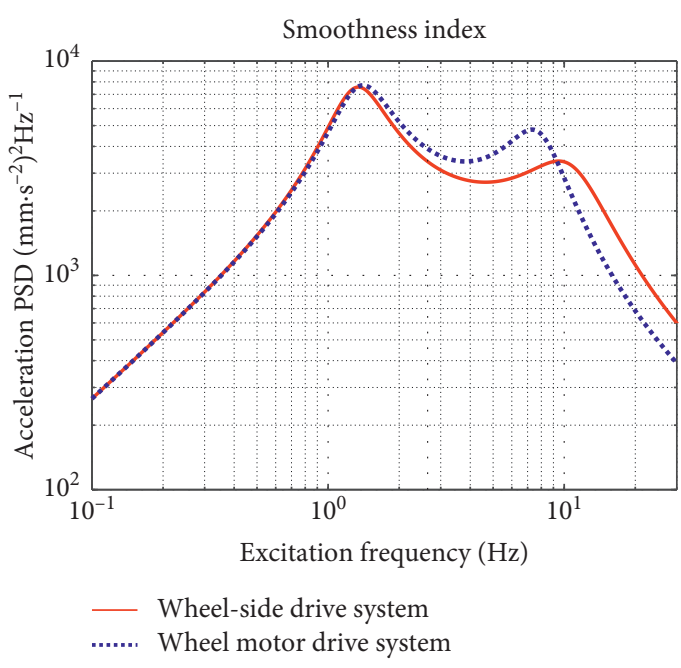

(a)

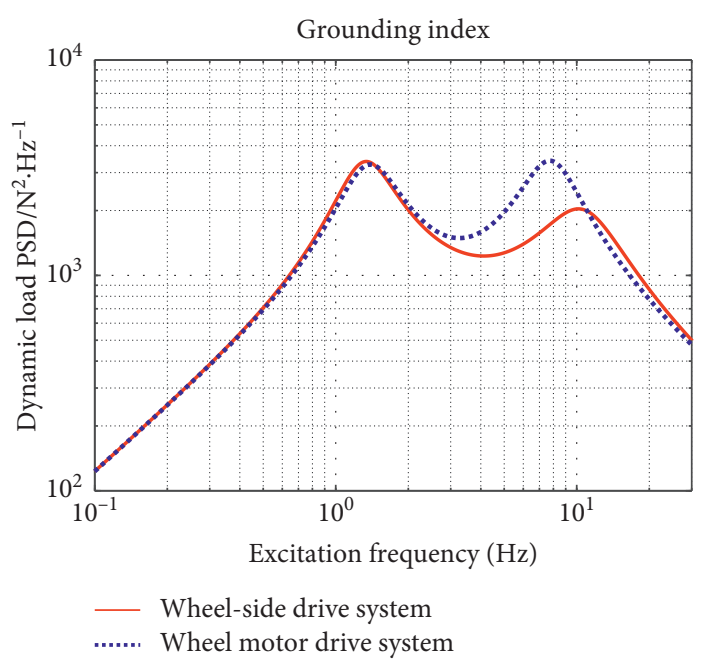

(b)

FIGURE 8: Vertical dynamics performance of different drive system arrangement schemes: (a) comparison of smoothness indicators between the integrated drive system and hub motor drive system and (b) grounding index comparison between the integrated drive system and hub motor drive system.

TABLE 7: Six-degree-of-freedom of bushing stiffnesses.

\begin{tabular}{|c|c|c|c|c|c|c|}
\hline Number & $\begin{array}{l}\text { Radial } x \text { stiffness } \\
(\mathrm{N} / \mathrm{mm})\end{array}$ & $\begin{array}{l}\text { Radial } y \text { stiffness } \\
(\mathrm{N} / \mathrm{mm})\end{array}$ & $\begin{array}{c}\text { Axial } z \text { stiffness } \\
(\mathrm{N} / \mathrm{mm})\end{array}$ & $\begin{array}{l}\text { Bending stiffness around } \\
\text { radial } x\left(\mathrm{~N} \mathrm{~mm} /{ }^{\circ}\right)\end{array}$ & $\begin{array}{l}\text { Bending stiffness around } \\
\text { radial } y\left(\mathrm{~N} \mathrm{~mm} /{ }^{\circ}\right)\end{array}$ & $\begin{array}{l}\text { Torsional stiffness } \\
\left(\mathrm{Nmm} /{ }^{\circ}\right)\end{array}$ \\
\hline $1 \#$ & 2098 & 2106 & 846 & 7284 & 7220 & 2532 \\
\hline $2-1 \#$ & 4878 & 6998 & 561 & 4165 & 4253 & 1841 \\
\hline $2-2 \#$ & 4878 & 6998 & 561 & 4165 & 4253 & 1841 \\
\hline $3 \#$ & 2928 & 2876 & 564 & 6027 & 6143 & 2772 \\
\hline $4 \#$ & 2285 & 4267 & 576 & 5542 & 7220 & 3165 \\
\hline $5 \#$ & 2285 & 2363 & 979 & 5542 & 4253 & 5547 \\
\hline $6 \#$ & 3565 & 2468 & 947 & 7092 & 7141 & 2915 \\
\hline
\end{tabular}

To verify the feasibility of applying the measured bushing parameters to the E-type multilink independent suspension, the spring damping and rubber bushing parameters were used to model the integrated E-type multilink suspension wheel-side drive system and analyze its elastic dynamics under braking force, lateral force, and return moment.

In the simulation process, the vehicle weight was $1.525 t$, the braking force linearly increased from 0 , the braking deceleration was set at $0.8 \mathrm{~g}$, and the axle load transfer was assumed to be $60 \%$. The rear wheel was subjected to a braking force of $2400 \mathrm{~N}$. To analyze the braking performance comprehensively, the rear wheel braking force was set as $3000 \mathrm{~N}$. The lateral force increased linearly from 0 , and the lateral acceleration was set as $0.6 \mathrm{~g}$. The lateral force was approximately $2100 \mathrm{~N}$. To comprehensively analyze the effect of the lateral force on the wheel toe-in, camber, and transverse longitudinal displacement of the wheel center, the rear wheel lateral force was set as $2500 \mathrm{~N}$. The return torque changed linearly. To comprehensively analyze the influence of the return torque on wheel toe-in, camber, and transverse longitudinal displacement of the wheel center, a torque range of -300 to $300 \mathrm{Nm}$ was considered.

The simulation yielded the total variations in wheel toe-in angle, wheel camber, wheel center transverse displacement, and wheel center longitudinal displacement for different external load conditions; the results are shown in Table 8.
As can be seen from Table 8, under the action of braking force, lateral force, and aligning torque, the changes in wheel toe-in angle and wheel camber angle were small, and the driving stability of the vehicle could be maintained. Moreover, the changes in the transverse and longitudinal displacements of the wheel center were small, the steering stability was adequate, and the tire wear was minimal.

4.3. Optimization Design of the Stiffness of the Bushing. In the process of vehicle driving, bushing stiffness has a great effect on the driving smoothness. On the design of suspension, there exists more freedom for bushing stiffness than the spring and damping. Therefore, optimization design of bushing stiffness can further improve the driving smoothness.

Design of experiment (DOE) was used for sensitivity analysis, and response surface method (RSM) was used for optimization design of bushing stiffness. In the E-type suspension, there were 7 bushings with 42 bushing stiffnesses. If all of the bushing stiffnesses were regarded as design variables in one optimization, computing times would reach $4 \times 10^{12}$, which did not meet the requirements of engineering practice. So, six-degree-freedom stiffnesses of each bushing were regarded as design variables in 
TABLe 8: Amount of variation in suspension performance parameters.

\begin{tabular}{|c|c|c|}
\hline Acting force & Suspension performance parameters & Quantity of change \\
\hline \multirow{4}{*}{ Braking force } & Wheel toe-in angle $\left(^{\circ}\right)$ & -0.096 \\
\hline & Wheel camber angle $\left(^{\circ}\right)$ & 0.20 \\
\hline & Wheel lateral displacement (mm) & 0.17 \\
\hline & Wheel longitudinal displacement (mm) & 1.35 \\
\hline \multirow{4}{*}{ Lateral force } & Wheel toe-in angle $\left({ }^{\circ}\right)$ & 0.038 \\
\hline & Wheel camber angle $\left({ }^{\circ}\right)$ & 0.82 \\
\hline & Wheel lateral displacement $(\mathrm{mm})$ & 0.29 \\
\hline & Wheel longitudinal displacement $(\mathrm{mm})$ & 0.23 \\
\hline \multirow{4}{*}{ Aligning torque } & Wheel toe-in angle $\left({ }^{\circ}\right)$ & -0.24 \\
\hline & Wheel camber angle $\left({ }^{\circ}\right)$ & -0.13 \\
\hline & Wheel lateral displacement (mm) & 0.52 \\
\hline & Wheel longitudinal displacement (mm) & 0.52 \\
\hline
\end{tabular}

a sensitivity analysis. Then, 6 factors which affect the driving smoothness mostly were chosen for optimization design. The evaluation index of ride comfort was the RMS of body acceleration.

4.3.1. Sensitivity Analysis for Bushing Stiffnesses. The sixdegree-freedom stiffnesses of bushing 5 were taken as an example. Class-B pavement was taken as the input. The power spectral density function of road roughness is

$$
G_{\dot{q}}(f)=(2 \pi f)^{2} G_{q}(f)=4 \pi^{2} G_{q}\left(n_{0}\right) n_{0}^{2} u,
$$

where $f$ is the frequency, $n_{0}$ is the reference frequency, and $n_{0}=0.1 . G_{q}\left(n_{0}\right)$ is the coefficient of road roughness, for Class-B pavement, $G_{q}\left(n_{0}\right)=64 \times 10^{-6} \mathrm{~m}^{3} . u$ is the speed of vehicle and $u=60 \mathrm{~km} / \mathrm{h}$.

The six-degree-of-freedom of stiffnesses of bushing 4 was set as design variable. The nominal value is shown in Table 8. The range of the design variables was set as $50 \%$ to $200 \%$ of the nominal value. The sensitivity analysis was carried out by ADAMS/Insight. The result is shown in Figure 9.

As shown in Figure 9, there exists great difference among the sensitivity of bushing stiffnesses in different directions. The sensitivity of radial $y$ stiffness and the radial $x$ stiffness are large, while the sensitivity of the axial $z$ stiffness is small.

The sensitivities of other bushings were analyzed in the same way, and the results were shown in Table 9. As shown in Table 9, the top six influencing factors were the radial $x$ stiffness of bushing 2-1, the radial $x$ stiffness, radial $y$ stiffness, bending stiffness around radial $x$ of bushing 4 , and the radial $x$ stiffness of bushing 7 . They were selected as the optimization variables.

4.3.2. Optimization of Bushing Stiffness. The RSM was used as the optimization method, and the Latin hypercube experimental design method was used to produce data samples. The cubic method was used to fit the relationship between the design variable and the optimization object. Then, regression model was obtained for optimization. The optimization result is shown in Table 10.

The body acceleration before and after optimization is shown in Figure 10. As shown in Figure 10, the body acceleration was markedly decreased using the optimized bushing stiffnesses. Simulation results indicated that the body vertical acceleration RMS decreased from 1088 to $802 \mathrm{~mm} / \mathrm{s}^{2}$, by $26.3 \%$ in the whole driving process.

The vertical acceleration PSD before and after optimization was shown in Figure 11. It can be seen that the vertical acceleration PSD decreased largely at about $8 \mathrm{~Hz}$. It meant that the peak PSD of the body acceleration near the inherent frequency of body vibration was significantly lower.

It can be seen that the max acceleration is $3.7 \mathrm{~m} / \mathrm{s}^{2}$, so the suspension dynamic deflection is

$$
l_{d}=\frac{m_{1 / 4} g}{k_{a}}=0.0265 \mathrm{~m}
$$

where $l_{d}$ is the suspension dynamic deflection, $m_{1 / 4}$ is the $1 / 4$ full-load body mass, and $k_{a}$ is the stiffness of the spring. It can be seen that the suspension dynamic deflection is far less than the limit of suspension dynamic deflection, $9 \mathrm{~cm}$ [28]. So this spring stiffness is feasible.

4.4. Lightweight Design of Wheel-Side Reducer Gears. As the wheel-side reducer housing acts as the trailing arm of the Etype multilink suspension, its mass is part of the unsprung mass of the vehicle. To maximally reduce the unsprung mass, the wheel-side reducer mass should be reduced. The mass of the reducer depends on the masses of the reducer housing, gears, shafts, and other parts, which themselves are mainly determined by the dimensions of the gears. Therefore, a lightweight design for the gears was considered to minimize the unsprung mass.

The aforementioned lightweighting is a nonlinear programming problem that can be optimized using MATLAB nonlinear programming tools. Nonlinear programming focuses on the extremal problem of an n-element real function subject to a set of constraints that can be equalities or inequalities. The general form of a nonlinear programming problem is

$$
\begin{array}{ll}
\text { Min } & f(X), \\
& g_{i}(X) \leq 0 \quad i=1,2, \ldots, m, \\
\text { s.t. } & h_{i}(X) \leq 0 \quad j=1,2, \ldots, l,
\end{array}
$$

where $f(X)$ is the object function; $X=\left(x_{1}, x_{2}, \ldots, x_{n}\right)^{T} \in E^{n} ; E^{n}$ is the space of solution vectors; and $f, g_{i}$, and $h_{j}$ are real-valued functions on $E^{n}$. 


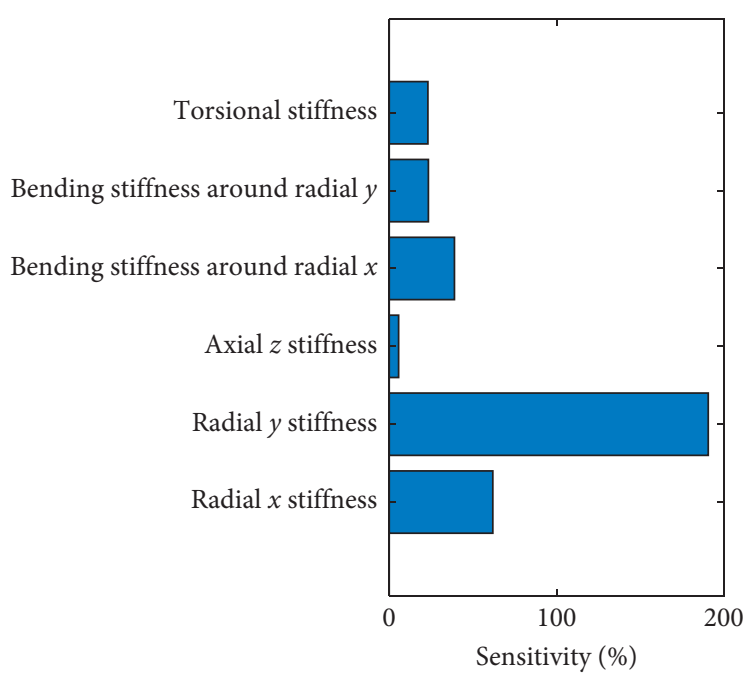

FIgURE 9: Sensitivity analysis of bushing 5.

TABLE 9: Six degree-of-freedom of bushing stiffnesses.

\begin{tabular}{lcccccc}
\hline Number & Radial $x$ stiffness & Radial $y$ stiffness & $\begin{array}{c}\text { Axial } z \\
\text { stiffness }\end{array}$ & Bending stiffness around radial $x$ & $\begin{array}{c}\text { Bending stiffness around } \\
\text { radial } y\end{array}$ & Torsional stiffness \\
\hline $1 \#$ & -21.57 & -28.78 & -7.81 & 10.32 & -8.96 & -2.47 \\
$2-1 \#$ & 25.03 & 3.83 & 9.14 & 21.06 & -11.44 & -3.18 \\
$2-2 \#$ & -5.23 & 1.4 & -8.19 & -15.07 & -13.44 & -17 \\
$3 \#$ & -77.62 & -2.93 & 12.03 & -15.5 & 11.47 & -17.5 \\
$4 \#$ & -39.8 & 11.85 & -22.19 & -26.84 & 23.38 & -23.09 \\
$5 \#$ & 61.88 & 190.6 & 5.59 & 38.95 & -37.38 & 35.58 \\
$6 \#$ & 11.13 & -9.87 & -36.54 & 0.45 & & \\
\hline
\end{tabular}

TABLE 10: Optimization result of bushing stiffnesses.

\begin{tabular}{lcccccc}
\hline Bushing & $\begin{array}{c}2-1 \# \\
\text { Bending stiffness } \\
\text { around radial } y \\
\left(\mathrm{~N} \cdot \mathrm{mm} /{ }^{\circ}\right)\end{array}$ & $\begin{array}{c}\text { R\# } \\
\text { stiffness }(\mathrm{N} / \mathrm{mm})\end{array}$ & $\begin{array}{c}4 \# \\
\text { Radial } x\end{array}$ & $\begin{array}{c}\text { Radial } x \\
\text { stiffness } \\
(\mathrm{N} / \mathrm{mm})\end{array}$ & $\begin{array}{c}\text { Radial } y \\
\text { stiffness } \\
(\mathrm{N} / \mathrm{m})\end{array}$ & $\begin{array}{c}\text { Bending stiffness around } \\
\text { radial } x\left(\mathrm{~N} \cdot \mathrm{mm} /{ }^{\circ}\right)\end{array}$ \\
\hline $\begin{array}{l}\text { Before } \\
\text { optimization }\end{array}$ & 4253 & 3565 & 4878 & 2285 & 4267 & 5542 \\
$\begin{array}{l}\text { After } \\
\text { optimization }\end{array}$ & 3589.8 & 1782.5 & 6031.9 & 3367.6 & 2741.3 & 2771 \\
\hline
\end{tabular}

The basic parameters of helical cylindrical gears include tooth number, modulus, pressure angle, helix angle, tooth width, displacement coefficient, and tooth top height coefficient. For a comprehensive analysis of the impact of each parameter on the strength, quality, noise, and other aspects of the reducer, the numbers of first and second master and driven gear teeth $\left(z_{1}, z_{2}, z_{3}\right.$, $z_{4}$ ), normal modulus of first and second master gear teeth $\left(m_{n 1}, m_{n 3}\right)$, helix angle of first and second master gear teeth $\left(\beta_{1}, \beta_{3}\right)$, and tooth width of first and second driven gear teeth $\left(b_{2}, b_{4}\right)$ were considered as design variables. Thus, the gears were designed to be lightweighted using MATLAB nonlinear programming function $f$ mincon, with the minimum sum of all gear indexing circle volumes as the objective function. The objective function is

$$
f(X)=\sum_{i=1}^{4} V_{i}=\sum_{i=1}^{4} \pi b_{i}\left(\frac{m_{n i} z_{i}}{2 \cos \beta_{i}}\right)^{2},
$$

where $V_{i}$ is the volume of each gear, $i=1,2,3,4$.

According to meshing condition of helical gear, the normal moduli are the same, the helix angle is equal, and the rotation direction is opposite. So, $m_{n 1}=m_{n 2}, m_{n 3}=m_{n 4}$; $\beta_{1}=\beta_{2}$, and $\beta_{3}=\beta_{4}$. The small gear is wider than the big gear. So, $b_{1}=b_{2}+3$ and $b_{3}=b_{4}+3$. At the same time, the transmission ratio of the reducer $i_{t}$ should be determined according to the performance of the selected wheel motor and the requirements of the target acceleration time, the maximum climbing slope and the maximum speed of the whole vehicle, which is a fixed value and not a design variable. So, $z_{4}=i_{t}$ $z_{1} z_{3} / z_{2}$. Then, formula (14) can be written as 


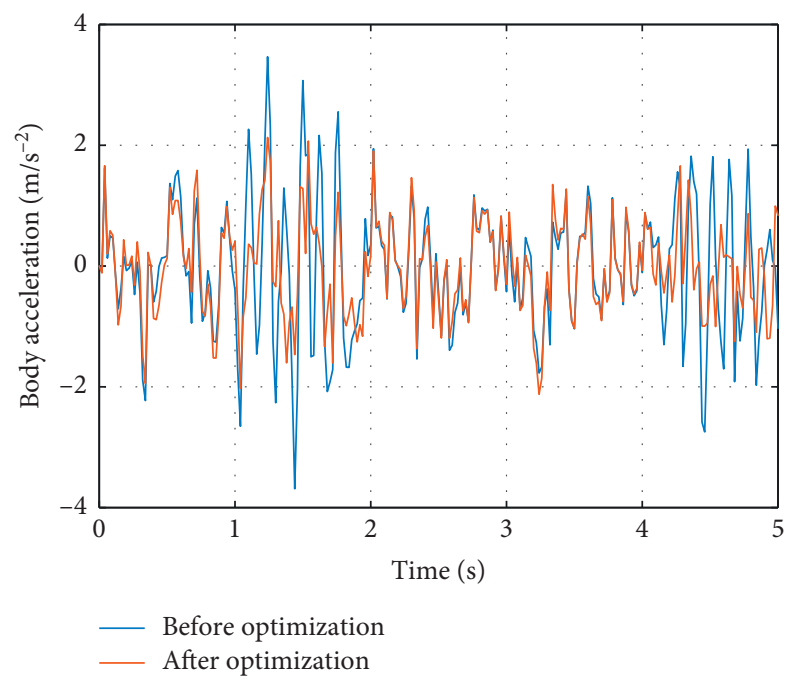

Figure 10: Body acceleration before and after optimization.

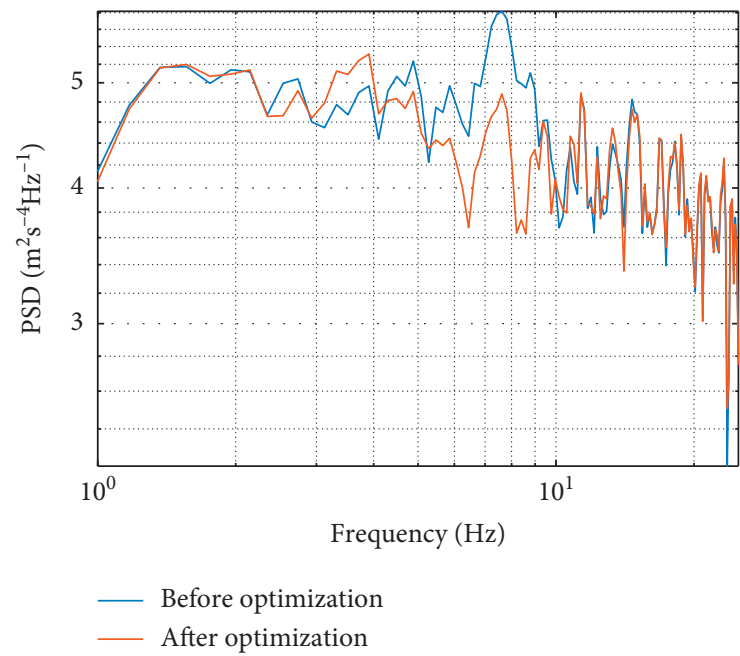

FIgURE 11: The PSD of the body acceleration before and after optimization.

$$
\begin{aligned}
f(X)= & \pi\left(b_{2}+3\right)\left(\frac{m_{n 1} z_{1}}{2 \cos \beta_{1}}\right)^{2}+\pi b_{2}\left(\frac{m_{n 1} z_{2}}{2 \cos \beta_{1}}\right)^{2} \\
& +\pi\left(b_{4}+3\right)\left(\frac{m_{n 3} z_{3}}{2 \cos \beta_{3}}\right)^{2}+\pi b_{4}\left(\frac{m_{n 3} i_{t} z_{1} z_{3}}{2 z_{2} \cos \beta_{3}}\right)^{2} .
\end{aligned}
$$

The design variable $X$ is

$$
\begin{aligned}
X & =\left[x_{1}, x_{2}, x_{3}, x_{4}, x_{5}, x_{6}, x_{7}, x_{8}, x_{9}\right]^{T}, \\
& =\left[z_{1}, z_{2}, z_{3}, m_{n 1}, m_{n 3}, \beta_{1}, \beta_{3}, b_{2}, b_{4}\right]^{T}
\end{aligned}
$$

In addition, no constraints in terms of root cutting, normal surface modulus, gear width, helix angle, tooth root bending fatigue strength, tooth surface contact fatigue strength, center distance, axial force similarity, and driven gear similar oil immersion were considered.
4.4.1. No Root Cutting Constraint Condition. The minimum number of teeth without undercutting is

$$
z_{\min }=\frac{2 h_{a}^{*}}{\sin ^{2} \alpha}
$$

where $z_{\min }$ is the minimum number of teeth, $h_{a}^{*}$ is addendum coefficient, and $\alpha$ is pressure angle.

When $h_{a}^{*}=1$ and $\alpha=20^{\circ}, z_{\min }=17$. For helical gear, the minimum number of teeth without undercutting is

$$
\frac{z_{i}}{\cos ^{3} \beta_{i}} \geq 17 \text {. }
$$

4.4.2. Constraint Condition for Normal Modulus. Taking lightweight and reducing working noise into consideration, the range of normal modulus is $\left[m_{n \min }, m_{n \text { max }}\right]$, where $m_{n \text { min }}$ and $m_{n \max }$ are the lower limit and upper limit, respectively. The constrain condition is 


$$
\begin{aligned}
& m_{n \text { min }}-m_{n 1} \leq 0, \\
& m_{n \text { min }}-m_{n 3} \leq 0, \\
& m_{n 1}-m_{n \text { max }} \leq 0, \\
& m_{n 3}-m_{n \text { max }} \leq 0 .
\end{aligned}
$$

4.4.3. Constraint Condition for Tooth Width. The width of helical gear is $b=k_{c} m_{n}$, and the range of tooth width factor $k_{c}$ is $\left[k_{c \min }, k_{c \max }\right]$, where $k_{c \text { min }}$ and $k_{c \text { max }}$ are the lower limit and upper limit, respectively. The constrain condition is

$$
\begin{aligned}
& k_{c \min }-\frac{b_{2}}{m_{n 1}} \leq 0, \\
& k_{c \min }-\frac{b_{4}}{m_{n 3}} \leq 0, \\
& \frac{b_{2}}{m_{n 1}}-k_{c \max } \leq 0, \\
& \frac{b_{4}}{m_{n 3}}-k_{c \max } \leq 0 .
\end{aligned}
$$

4.4.4. Constraint Condition for Helix Angle. The helix angle ranges of the first- and the second-level gears are $\left[\beta_{1 \text { min }}, \beta_{1 \text { max }}\right]$ and $\left[\beta_{3 \min }, \beta_{3 \max }\right]$, respectively. The constrain condition is

$$
\begin{aligned}
& \beta_{1 \text { min }}-\beta_{1} \leq 0, \\
& \beta_{1}-\beta_{1 \text { max }} \leq 0, \\
& \beta_{3 \min }-\beta_{3} \leq 0, \\
& \beta_{3}-\beta_{3 \max } \leq 0 .
\end{aligned}
$$

4.4.5. Constraint Condition for Bending Strength of Gear Tooth. Bending stress of helical gear can be calculated as

$$
\sigma_{w}=\frac{2 T \cos \beta K_{\sigma}}{\pi z m_{n}^{3} y K_{c} K_{\varepsilon}}
$$

where $T$ is the load, $K_{\sigma}$ is the stress concentration factor, and $K_{\sigma}=1.5, y$ is the tooth form factor, $K_{c}$ is the tooth width factor, and $K_{c}=b / m_{n}, K_{\varepsilon}$ is the contact ratio factor and $K_{\varepsilon}=0$.

For a pair of meshing gears, the bending stress of the driving gear is relatively large, so the constraint condition is determined by the bending stress of the first and second driving gears. $\left|\sigma_{w 1}\right|$ and $\left|\sigma_{w 3}\right|$ are the allowable bending stress of the first and second gears, respectively.

$$
\begin{gathered}
\frac{2 T \cos \beta_{1} K_{\sigma}}{\pi z_{1} m_{n 1}^{3} y_{1} K_{c} K_{\varepsilon}}-\left|\sigma_{w 1}\right| \leq 0, \\
\frac{2 T z_{2} \cos \beta_{3} K_{\sigma}}{\pi z_{1} z_{3} m_{n 3}^{3} y_{3} K_{c} K_{\varepsilon}}-\left|\sigma_{w 3}\right| \leq 0 .
\end{gathered}
$$

4.4.6. Constraint Condition for Contact Fatigue Strength of Tooth Surface. Contact stress of gear $\sigma_{j}$ is

$$
\sigma_{j}=0.418 \sqrt{\frac{F_{n} E}{b}\left(\frac{1}{\rho_{z}}+\frac{1}{\rho_{b}}\right)},
$$

where $F_{n}$ is the normal force on tooth surface and $E$ is the elastic modulus of gear material. $b$ is the actual contact width of the meshing gears; $\rho_{z}$ and $\rho_{b}$ are the radius of pitch circle of driving gear and driven gear. The constrain condition is

$$
\begin{aligned}
& 0.418 \sqrt{\frac{F_{n 1} E}{b_{2}}\left(\frac{\cos ^{2} \beta_{1}}{r_{1} \sin \alpha}+\frac{\cos ^{2} \beta_{1}}{r_{2} \sin \alpha}\right)}-\left|\sigma_{j}\right|<0, \\
& 0.418 \sqrt{\frac{F_{n 2} E}{b_{4}}\left(\frac{\cos ^{2} \beta_{3}}{r_{3} \sin \alpha}+\frac{\cos ^{2} \beta_{3}}{r_{4} \sin \alpha}\right)}-\left|\sigma_{j}\right|<0 .
\end{aligned}
$$

where $F_{n 1}$ and $F_{n 2}$ are normal force of the first-level and second-level gears on tooth surface respectively, and $\left|\sigma_{j}\right|$ is the allowable contact stress.

4.4.7. Constraint Condition for Gear Center Distance. Taking the length of integrate trailing arm and the bearing capacity of gears, the two-level center distances are

$$
265 \leq\left(a_{1}+a_{2}\right) \leq 275,
$$

where $a_{1}$ and $a_{2}$ are the first- and the second-center distances, respectively.

Therefore, the constraint conditions can be obtained as

$$
265 \leq \frac{\left(z_{1}+z_{2}\right) m_{n 1}}{\cos \beta_{1}}+\frac{\left(z_{3}+i_{t} z_{1} z_{3} / z_{2}\right) m_{n 3}}{\cos \beta_{3}} \leq 275 .
$$

4.4.8. Constraint Condition for Axial Force. Helical gear transmission produces axial force. In order to prevent excessive axial force on the intermediate shaft, the axial force on the intermediate shaft is constrained.

$$
\left|F_{a 2}-F_{a 3}\right| \leq 600,
$$

where $F_{a 2}$ is the axial force of the first-level driven gear and $F_{a 3}$ is the axial force of the second-level driving gear. The constrain condition can be obtained as follows:

$$
\begin{aligned}
& \left(\frac{2 T \sin \beta_{1}}{m_{n 1} z_{1}}-\frac{2 T z_{2} \sin \beta_{3}}{z_{1} z_{3} m_{n 3}}\right)-600 \leq 0, \\
& \left(\frac{2 T z_{2} \sin \beta_{3}}{z_{1} z_{3} m_{n 3}}-\frac{2 T \sin \beta_{1}}{m_{n 1} z_{1}}\right)-600 \leq 0 .
\end{aligned}
$$

4.4.9. Constraint Condition for Immersion Depth of Driven Gear. In order to make the oil immersion depth of the firstlevel reduction-driven gear similar to that of the second-level driven gear, the diameter of the driven gear should also be similar. 


$$
\left|d_{2}-d_{4}\right| \leq 20 \mathrm{~mm}
$$

where $d_{2}$ and $d_{4}$ are the diameter of the first- and the secondlevel driven gear base circle, respectively. The constrain condition can be obtained as follows:

$$
\begin{aligned}
& \left(\frac{z_{2} m_{n 1}}{\cos \beta_{1}}-\frac{z_{4} m_{n 3}}{\cos \beta_{3}}\right)-20 \leq 0, \\
& \left(\frac{z_{4} m_{n 3}}{\cos \beta_{3}}-\frac{z_{2} m_{n 1}}{\cos \beta_{1}}\right)-20 \leq 0 .
\end{aligned}
$$

The optimization results and their approximated values are shown in Table 11.

The gear parameters before and after optimization were compared, as shown in Table 12.

The gear material utilized was 20CrMnTi with a density of $7.8 \times 10^{3} \mathrm{~kg} / \mathrm{m}^{3}$. Before optimization, the sum of the volumes of the four gears was $1.401 \times 10^{6} \mathrm{~mm}^{3}$, and the sum of the masses was approximately $10.93 \mathrm{~kg}$. The corresponding values after optimization were $8.411 \times 10^{5} \mathrm{~mm}^{3}$ and $6.56 \mathrm{~kg}$. Thus, the optimization provided a reduction of $60.02 \%$ in the mass of the gear, which is highly beneficial for reducing the unsprung mass.

\section{Design and Strength Verification of Each Component}

According to the optimized design of the hard point coordinates of each control arm, the structures of the upper, front-lower, and rear-lower control arms were designed considering the force, space arrangement, and lightweight of each control arm. For the connection between the reducer housing and the rubber bushing, the bushing adapter plate was designed to accommodate the relative dimensions of the hinge point and reducer housing, as well as the requirements for arrangement of the rubber bushing. To mount the upper, front-lower, and rear-lower control arms on the reducer housing and to ensure an appropriate spatial orientation attitude for each control arm, a connector for each control arm was required. To mount each control arm connector to the reducer housing, threaded holes were cut in the corresponding positions on the side of the reducer housing, and bolts were used for connection. The components were fabricated using 45 steel and are listed in Table 13.

The final structural solution of the integrated E-type multilink suspension wheel-side drive system is shown in Figure 12.

To calculate the strength of each component of the integrated E-type multilink suspension wheel-side drive system, the force acting at the point of contact between the wheels and the ground while the car is moving was used for analysis. To calculate the static strength, four typical limit conditions, namely maximum drive force, steering side slip, uneven road surface, and emergency braking, were selected for the force analysis. The results of the force analysis were applied to the model to analyze the strength of each part. According to the preliminary findings, all the vehicle parameters used for simulation are listed in Table 14 .
TABLE 11: Gear parameters' optimization results.

\begin{tabular}{lcc}
\hline $\begin{array}{l}\text { Gear } \\
\text { parameters }\end{array}$ & $\begin{array}{c}\text { MATLAB optimization } \\
\text { results }\end{array}$ & $\begin{array}{c}\text { Approximated } \\
\text { results }\end{array}$ \\
\hline$z_{1}$ & 37.8639 & 38 \\
$z_{2}$ & 102.983 & 103 \\
$z_{3}$ & 35.1832 & 34 \\
$z_{4}$ & 85.389 & 85 \\
$b_{2}$ & $9 \mathrm{~mm}$ & $9 \mathrm{~mm}$ \\
$b_{4}$ & $12.7606 \mathrm{~mm}$ & $14 \mathrm{~mm}$ \\
$m_{n 1}$ & $1.5 \mathrm{~mm}$ & $1.5 \mathrm{~mm}$ \\
$m_{n 3}$ & $2.1268 \mathrm{~mm}$ & $2.25 \mathrm{~mm}$ \\
$\beta_{1}$ & $34^{\circ}$ & $34^{\circ}$ \\
$\beta_{3}$ & $21.2591^{\circ}$ & $21^{\circ}$ \\
\hline
\end{tabular}

5.1. Maximum Driving Force. Under the maximum driving torque to the wheels, the maximum unilateral driving force is

$$
F_{X}=\frac{T_{\max } i_{t}}{R}=\frac{90 \times 6.6}{0.36215}=1640 \mathrm{~N}<\frac{1}{2} m_{r} g \varphi,
$$

where $F_{X}$ is the maximum unilateral driving force.

The corresponding vertical force on the unilateral wheel is

$$
\begin{aligned}
F_{Z} & =\frac{1}{2}\left(m_{r} g+2 F_{x} \frac{h_{g}}{L}\right), \\
& =\frac{1}{2}\left(950 \times 9.8+2 \times 1640 \times \frac{600}{2660}\right)=5025 \mathrm{~N} .
\end{aligned}
$$

where $F_{Z}$ is the corresponding vertical force on the unilateral wheel.

5.2. Steering Side-Slip Operation. During steering side-slip operation, the system is subjected to lateral and vertical forces. The vertical force on the lateral wheels is

$$
F_{Z}=\frac{m_{r} g}{2}\left(1+\frac{\varphi h_{g}}{B}\right)=\frac{950 \times 9.8}{2}\left(1+\frac{0.8 \times 600}{1570}\right)=6078 \mathrm{~N} \text {. }
$$

The corresponding lateral force at the wheel ground connection joint on this side is

$$
F_{Y}=F_{Z} \varphi=6078 \times 0.8=4863 \mathrm{~N},
$$

where $F_{Y}$ is the corresponding lateral force at the wheel ground connection joint on this side.

5.3. Uneven Road Conditions. When traversing uneven roads, the wheel joints are mainly subjected to impact loads from the ground.

The vertical force on one side of the rear wheel is

$$
F_{Z}=\frac{1}{2} k_{d} m_{r} g=0.5 \times 1.5 \times 950 \times 9.8=6983 \mathrm{~N},
$$

where $k_{d}$ is the dynamic load factor, which was set as 1.5 in this study. 
TABLE 12: Comparison of gears before and after optimization.

\begin{tabular}{|c|c|c|c|c|c|}
\hline & & \multicolumn{2}{|c|}{ First level } & \multicolumn{2}{|c|}{ Second level } \\
\hline & & Driving gear & Driven gear & Driving gear & Driven gear \\
\hline \multirow{7}{*}{ Preoptimization gear parameters } & Number of teeth & 31 & 78 & 29 & 76 \\
\hline & Normal modulus (mm) & 2.1 & 2.1 & 2.3 & 2.3 \\
\hline & Tooth width $(\mathrm{mm})$ & 20 & 18 & 25 & 23 \\
\hline & Helix angle $\left({ }^{\circ}\right)$ & 34 & 34 & 22 & 22 \\
\hline & Volume of each gear $\left(\mathrm{mm}^{3}\right)$ & $1.017 \times 10^{5}$ & $5.519 \times 10^{5}$ & $1.057 \times 10^{5}$ & $6.421 \times 10^{5}$ \\
\hline & Total volume $\left(\mathrm{mm}^{3}\right)$ & \multicolumn{4}{|c|}{$1.401 \times 10^{6}$} \\
\hline & Total mass $(\mathrm{kg})$ & \multicolumn{4}{|c|}{10.93} \\
\hline \multirow{7}{*}{ Postoptimization gear parameters } & Number of teeth & 38 & 103 & 34 & 85 \\
\hline & Normal modulus (mm) & 1.5 & 1.5 & 2.25 & 2.25 \\
\hline & Tooth width $(\mathrm{mm})$ & 12 & 9 & 17 & 14 \\
\hline & Helix angle $\left({ }^{\circ}\right)$ & 34 & 34 & 21 & 21 \\
\hline & Volume of each gear $\left(\mathrm{mm}^{3}\right)$ & $4.455 \times 10^{4}$ & $2.455 \times 10^{5}$ & $8.965 \times 10^{4}$ & $4.614 \times 10^{5}$ \\
\hline & Total volume $\left(\mathrm{mm}^{3}\right)$ & \multicolumn{4}{|c|}{$8.411 \times 10^{5}$} \\
\hline & Total mass $(\mathrm{kg})$ & \multicolumn{4}{|c|}{6.56} \\
\hline
\end{tabular}

TABLE 13: Structural design of each component.

Front-lower control arm

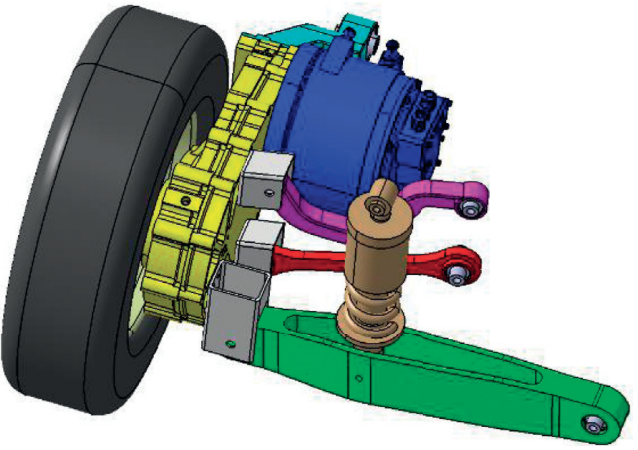

FIGURE 12: Integrated E-type multilink suspension wheel-side drive system.
TABLE 14: Overall vehicle parameters.

\begin{tabular}{lc}
\hline Parameter & Value \\
\hline Overall vehicle mass, $m(\mathrm{~kg})$ & 1525 \\
Wheelbase, $L(\mathrm{~mm})$ & 2660 \\
Rear wheelbase, $B(\mathrm{~mm})$ & 1570 \\
Full mass to front-axle distance, $L_{f}(\mathrm{~mm})$ & 1300 \\
Maximum driving torque, $T_{\max }(\mathrm{Nm})$ & 90 \\
Fully loaded rear-axle mass, $m_{r}(\mathrm{~kg})$ & 950 \\
Capacity, 5 people $(\mathrm{kg})$ & 300 \\
Full mass height, $h_{g}(\mathrm{~mm})$ & 600 \\
Wheel radius, $R(\mathrm{~mm})$ & 362.15 \\
Road surface adhesion coefficient, $\varphi$ & 0.8 \\
Reduction ratio, $i$ & 6.6 \\
Tire parameters & $225 / 65 \mathrm{R} 17$ \\
\hline
\end{tabular}


TABLE 15: Forces at each node under different working conditions.

\begin{tabular}{|c|c|c|c|c|}
\hline Loading point & Working condition & $F x / \mathrm{N}$ & $\mathrm{Fy} / \mathrm{N}$ & $\mathrm{Fz} / \mathrm{N}$ \\
\hline \multirow{4}{*}{ Trailing arm-upper control arm hinge point } & Max. driving force working conditions & 271 & -1185 & 73 \\
\hline & Steering slippage conditions & -866 & 4852 & -897 \\
\hline & Uneven road surface conditions & 282 & -1647 & 332 \\
\hline & Emergency braking conditions & 36 & -148 & 3 \\
\hline \multirow{4}{*}{ Trailing arm-front-lower control arm hinge point } & Max. driving force working conditions & 34 & -148 & -12 \\
\hline & Steering slippage conditions & 1393 & -5638 & 237 \\
\hline & Uneven road surface conditions & -409 & 1643 & -97 \\
\hline & Emergency braking conditions & -387 & 1762 & 212 \\
\hline \multirow{4}{*}{ Trailing arm-rear-lower control arm hinge point } & Max. driving force working conditions & -241 & 1333 & -3962 \\
\hline & Steering slippage conditions & -166 & -4075 & -5108 \\
\hline & Uneven road surface conditions & -284 & 7 & -6125 \\
\hline & Emergency braking conditions & -6125 & -178 & -1614 \\
\hline \multirow{4}{*}{ Upper control arm-trailing arm hinge point } & Max. driving force working conditions & 1217 & - & - \\
\hline & Steering slippage conditions & -5010 & - & - \\
\hline & Uneven road surface conditions & 1704 & - & - \\
\hline & Emergency braking conditions & 152 & - & - \\
\hline \multirow{4}{*}{ Front-lower control arm-trailing arm hinge point } & Max. driving force working conditions & 152 & - & - \\
\hline & Steering slippage conditions & 5812 & - & - \\
\hline & Uneven road surface conditions & -1696 & - & - \\
\hline & Emergency braking conditions & -1816 & - & - \\
\hline \multirow{4}{*}{ Rear-lower control arm-trailing arm hinge point } & Max. driving force working conditions & -1219 & 2063 & 3433 \\
\hline & Steering slippage conditions & 3754 & -4058 & 3487 \\
\hline & Uneven road surface conditions & -458 & -6065 & 776 \\
\hline & Emergency braking conditions & 1823 & 3115 & 1724 \\
\hline \multirow{4}{*}{ Spring support point on rear-lower control arm } & Max. driving force working conditions & 56 & -6232 & -338 \\
\hline & Steering slippage conditions & -8344 & -428 & 109 \\
\hline & Uneven road surface conditions & 109 & -8627 & -445 \\
\hline & Emergency braking conditions & -445 & 55 & -5545 \\
\hline
\end{tabular}

5.4. Emergency Braking Conditions. Assuming a vehicle synchronous adhesion coefficient $\varphi_{0}=0.7$ and emergency braking on a road surface with an adhesion coefficient of $\varphi=0.8$, when the rear wheel has just become locked, the force of the suspension guidance mechanism and each kinematic pair reaches its maximum values. At this time, the braking strength is

$$
z=\frac{\varphi L_{f}}{L_{f}+\left(\varphi-\varphi_{0}\right) h_{g}}=\frac{0.8 \times 1300}{1300+(0.8-0.7) \times 600}=0.765 .
$$

The vertical force on one side of the wheel is

$$
\begin{aligned}
F_{Z} & =\frac{1}{2} m_{r} g\left(1-\frac{z h_{g}}{L_{f}}\right) \\
& =\frac{1}{2} \times 950 \times 9.8 \times\left(1-\frac{0.765 \times 600}{1300}\right)=3011 \mathrm{~N} .
\end{aligned}
$$

The unilateral braking force size is

$$
F_{X}=\varphi F_{Z}=0.8 \times 3011=2409 \mathrm{~N} .
$$

The braking torque applied to the wheel is

$$
M=F_{X} R=2409 \times 0.36215=872 \mathrm{~N} \cdot \mathrm{m} .
$$

The preload of the spring was considered as $5260.6 \mathrm{~N}$, and the force at each node was calculated using ADAMS for each limit condition of the suspension. The results are shown in Table 15.

In this case, on the integrated trailing arm assembly, the motor is made of gray cast iron, the reducer housing is made of aluminum alloy 6061-T6, and the other components are made of 45 steel. As the motor is not subjected to excitation from the road surface in this system and as the design and manufacturing process of the motor housing are different from those of the other components and are not the focus of this study, stress analysis of the motor was not performed. The tensile strengths of 6061T6 aluminum alloy and 45 steel are 276 and $360 \mathrm{MPa}$, respectively. The allowable stress $[\sigma]$ can be calculated using the following equation:

$$
[\sigma]=\frac{\sigma_{s}}{s}
$$

where $\sigma_{s}$ is the yield strength and $s$ is the safety factor.

According to Equation (41), the allowable stress of 6061T6 aluminum alloy is $[\sigma]_{6601}=184 \mathrm{MPa}$ and that of 45 steel is $[\sigma]_{45}=240 \mathrm{MPa}$.

A static analysis using the ANSYS WORKBENCH simulation platform was performed to determine the maximum stresses applied to each component node; the results are shown in Table 16.

From Table 16, it is verified that the strength of each member meets the design requirements. 
TABLe 16: Maximum stress on each component node under different working conditions.

\begin{tabular}{|c|c|c|}
\hline Component & Working condition & Maximum stress at the node $(\mathrm{MPa})$ \\
\hline \multirow{4}{*}{ Reducer housing } & Max. driving force working conditions & 108.50 \\
\hline & Steering slippage conditions & 145.22 \\
\hline & Uneven road surface conditions & 64.44 \\
\hline & Emergency braking conditions & 59.37 \\
\hline \multirow{4}{*}{ Half-shaft bushings } & Max. driving force working conditions & 36.87 \\
\hline & Steering slippage conditions & 86.13 \\
\hline & Uneven road surface conditions & 28.04 \\
\hline & Emergency braking conditions & 47.23 \\
\hline \multirow{4}{*}{ Bushing adapter plate } & Max. driving force working conditions & 91.38 \\
\hline & Steering slippage conditions & 52.96 \\
\hline & Uneven road surface conditions & 62.24 \\
\hline & Emergency braking conditions & 41.01 \\
\hline \multirow{4}{*}{ Each control arm connector } & Max. driving force working conditions & 138.55 \\
\hline & Steering slippage conditions & 230.35 \\
\hline & Uneven road surface conditions & 172.28 \\
\hline & Emergency braking conditions & 136.63 \\
\hline \multirow{4}{*}{ Upper control arm } & Max. driving force working conditions & 55.10 \\
\hline & Steering slippage conditions & 226.85 \\
\hline & Uneven road surface conditions & 77.16 \\
\hline & Emergency braking conditions & 6.88 \\
\hline \multirow{4}{*}{ Front-lower control arm } & Max. driving force working conditions & 3.18 \\
\hline & Steering slippage conditions & 121.43 \\
\hline & Uneven road surface conditions & 35.43 \\
\hline & Emergency braking conditions & 37.94 \\
\hline \multirow{4}{*}{ Rear-lower control arm } & Max. driving force working conditions & 161.23 \\
\hline & Steering slippage conditions & 232.00 \\
\hline & Uneven road surface conditions & 203.76 \\
\hline & Emergency braking conditions & 88.99 \\
\hline
\end{tabular}

\section{Conclusion}

To suppress the negative effect of the unsprung mass, the integrated E-type multilink independent suspension was designed and optimized. A comparison between the integrated E-type multilink wheel-side drive system and a hub motor drive system with equal mass and the same parameters were carried out by multibody system dynamic simulation. The results showed that the proposed solution could effectively suppress the negative effect of the unsprung mass. The main findings of this study are as follows:

(1) Based on the idea of integrating an independent suspension guiding mechanism with a wheel-side electric drive system, an integrated E-type link suspension wheel-side drive system scheme was proposed herein. Then, the structural form of the integrated E-type link suspension wheel-side drive system was determined based on the mechanism topology theory and the orientation feature set method.

(2) A multibody dynamics model of the integrated Etype multilink suspension wheel-side drive system was established in ADAMS, with wheel camber, wheel toe-in angle, and wheelbase variation as the optimization objectives and suspension hard point parameters as the optimization variables. A sensitivity analysis of the optimization variables was performed using ADAMS/Insight, and reasonable optimization variables were selected based on the results. Based on the obtained optimization variables, the objective function was fitted using ADAMS/Insight, and the total unified objective function was established using the unified objective method. Subsequently, using the MATLAB genetic algorithm optimization toolbox, feasible suspension hard point parameters for the integrated E-type multilink suspension wheel-side drive system were obtained.

(3) The spring damper arrangement was determined, and the spring stiffness and damping were matched to obtain a system spring stiffness of $64,572 \mathrm{~N} / \mathrm{m}$ and damping of $4846 \mathrm{~N} \mathrm{~s} / \mathrm{m}$. A comparison between the integrated E-type multilink wheel-side drive system and a hub motor drive system with equal mass and the same parameters showed that the proposed solution could effectively suppress the negative effect of the unsprung mass. Subsequently, a bushing stiffness measurement test was performed to determine the required stiffnesses of the bushings; then, the relevant bushings were applied to each kinematic pair of the integrated E-type multilink suspension wheelside drive system. Finally, a simulation analysis of the suspension dynamics was conducted to verify the reasonableness of the bushing parameters obtained 
via the tests, and the sensitivity analysis and optimization of bushing stiffness were carried out by RSM to further improve the ride smoothness.

(4) A preliminary structural scheme of the integrated Etype multilink suspension wheel-side electric drive system was established. Subsequently, the design variables, constraints, and objective functions for the optimal gear design of the helical gear were determined, and a nonlinear optimization function was adopted to produce a lightweight design for the gears of the wheel-side reducer.

(5) A structural design and static strength verifications were performed for the integrated E-type multilink suspension wheel-side drive system. It was verified that the strength of all components met the design requirements.

\section{Data Availability}

The figure and table of simulation results used to support the findings of this study are included within the article.

\section{Conflicts of Interest}

The authors declare that they have no conflicts of interest.

\section{Acknowledgments}

The authors would like to thank the National Natural Science Foundation of China (grant no. 51375344) for their support.

\section{References}

[1] H. Yoshida and H. Shimizu, "Development of high performance electric vehicle "Eliica," Koyo Engineering Journal English Edition, vol. 26, pp. 13-19, 2006.

[2] J. Zhu, Z. Wang, L. Zhang, and D. G. Dorrell, "Braking/ steering coordination control for in-wheel motor drive electric vehicles based on nonlinear model predictive control," Mechanism and Machine Theory, vol. 142, no. 142, Article ID 103586, 2019.

[3] L. Zhang, Y. Wang, and Z. Wang, "Robust lateral motion control for in-wheel-motor-drive electric vehicles with network induced delays," IEEE Transactions on Vehicular Technology, vol. 68, no. 11, pp. 10585-10593, 2019.

[4] J. Wang, Q. Wang, L. Jin, and C. Song, "Independent wheel torque control of $4 \mathrm{WD}$ electric vehicle for differential drive assisted steering," Mechatronics, vol. 21, no. 1, pp. 63-76, 2011.

[5] S. Ding, L. Liu, and W. X. Zheng, "Sliding mode direct yawmoment control design for in-wheel electric vehicles," IEEE Transactions on Industrial Electronics, vol. 64, no. 8, pp. 6752-6762, 2017.

[6] J. Wu, Z. Wang, and L. Zhang, "Unbiased-estimation-based and computation-efficient adaptive MPC for four-wheel-independently-actuated electric vehicles," Mechanism and Machine Theory, vol. 154, Article ID 104100, 2020.

[7] X. Ding, Z. Wang, and L. Zhang, "Hybrid control-based acceleration slip regulation for four-wheel-independentlyactuated electric vehicles," IEEE Transactions on Transportation Electrification, p. 1, 2019.
[8] C. Zhang, M. Liu, and Z. Wang, "Effects of the unsprung mass on vehicles," Journal of Beijing Institute of Technology (Social Sciences Edition), vol. 20, pp. 49-53, 2011.

[9] M. Liu, C. Zhang, and Z. Wang, "Research on the influence of unsprung mass on vehicle handling stability," in Proceedings of the 2012 International Conference on Materials Engineering and Automatic Control, Jinan, China, August 2012.

[10] X. Chen, L. Wang, Z. Zhong et al., "Structure and method of reducing equivalent unsprung mass of wheel side electric drive system of single oblique arm suspension," CN102092255A, 2011.

[11] http://www.engadget.com/2006/08/12siemensvdoshowsoffec ornermotorinhubconcept $[\mathrm{EB} / \mathrm{OL}]$.

[12] http://www.autohome.com.cn/tech/201212/434072.html[EB/ OL].

[13] G. Ning and G. Wan, "The present research situation of the influences on vehicle vertical performances induced by direct wheel drives system," Automobile Technology, vol. 37803, pp. 21-25, 2007.

[14] F. Profumo, Z. Zhang, and A. Tenconi, "Axial flux machines drives: a new viable solution for electric cars," IEEE Transactions on Industrial Electronics, vol. 44, no. 1, pp. 39-45, 1997.

[15] S. Hai, "Revolutionary design for EV michelin active wheel," Automobile \& Parts, vol. 52, pp. 36-37, 2009.

[16] C. Xia and B. Ning, "Active control of vertical vibration negative influences induced by high unsprung mass of inwheel motor electric vehicle," Chinese Journal of Construction Machinery, vol. 4, no. 1, pp. 31-34+42, 2006.

[17] J. H. Lumkes, Design, Simulation, and Testing of an Energy Storage Hydrostatic Vehicle Transmission and Controller, University of Wisconsin--Madison, Madison, WI, USA, 1997.

[18] W. Wang, Y. Li, S. Zhang, and B. Wang, "Research on the ride comfort of electric drive system based on double trailing arm suspension," Applied Mechanics and Materials, vol. 607, pp. 458-466, 2014.

[19] X. Chen, F. Tang, Z. Zhong et al., "Structure and method of reducing equivalent unsprung mass of single wishbone suspension wheel side electric drive system," 201110053093.0, 2011.

[20] X. Chen, F. Tang, and Z. Zhong, "Research on ride comfort and ground adhesion of an electric wheel drive system for single trailing arm," Mechatronics, vol. 18, no. 9, pp. 22-26, 2012.

[21] X. Chen, F. Tang, Z. Zhong et al., "Integrated single trailing arm suspension deceleration wheel side electric drive system," 201120232030.7, 2012.

[22] X. Chen, F. Tang, Z. Zhong et al., "Integrated mcPherson suspension with in wheel deceleration electric drive system," 201210389230.2, 2013.

[23] X. Chen, F. Tang, Z. Zhong et al., "Integrated double wishbone suspension deceleration wheel side electric drive system," 201210388943.7, 2013.

[24] X. Chen, W. Wei, and X. Wang, "Research on vertical dynamics of electric drive systems with inhibition of negative effects of unsprung mass," Chinese Journal of Automotive Engineering, vol. 4, pp. 430-437, 2014.

[25] X. Chen, J. Yin, W. Wang, L. Wu, and F. Tang, "Approaches to diminish large unsprung mass negative effects of wheel side drive electric vehicles," Journal of Advanced Mechanical Design, Systems, and Manufacturing, vol. 10, no. 4, Article ID JAMDSM0064, 2016.

[26] X. ChenW. Wang et al., "The analysis and design of the topological structure of the automobile independent suspension 
steering mechanism base on single open chain unit," in Proceedings of 2014 Workshop on Fundamental Issues and Future Research Directions for Parallel Mechanisms and Manipulators, Tianjin, China, July 2014.

[27] W. Wang, The Research and Application on Topological Structure of Integrated Suspension Electrical Wheel Drive System, Tongji University, Shanghai, China, 2015.

[28] X. Wang, Automobile Chassis Design, Tsinghua University Press, Beijing, China, 2010.

[29] X. Chen, L. Wang, and P. Zhao, "Design and development of A measuring device to measure the static stiffness characteristic of the rubber bushing in each direction in suspension system," Mechatronics, vol. 19, no. 12, pp. 52-57, 2013. 